These were taken at multiple time points (baseline, 6 and 24 hours post procedure). Calculated volumetric parameters included $3 \mathrm{D}$ enddiastolic volume (EDV) and end-systolic volume (ESV), stroke volume (SV) and 3D LA volume (LAV). Diastolic function was monitored using the indices mean E:E' and systolic function/ contractility was measured with $\mathrm{dP} / \mathrm{dt}$ max and early peak systolic velocity $\left(\mathrm{S}^{\prime}\right)$. The FloTrac system (consisting of the Vigileo monitor and sensor), uses a clinically validated algorithm to provide continuous cardiac output (CO), stroke volume (SV) and systemic vascular resistance in real-time.

Results TAVI resulted in an immediate increase in cardiac output (3.7 (baseline), 4.6 (6 h) 4.5 l/min ( $24 \mathrm{~h}), \mathrm{p}<0.5$ baseline vs $6 \mathrm{~h}$ and $24 \mathrm{~h})$ with no significant change in systemic vascular resistance (1162, 1292 and 1367 dyn*s/cm ${ }^{5}$ ). However, $6 \mathrm{~h}$ post-TAVI there was a significant decrease in systolic function as measured by $\mathrm{dP} / \mathrm{dt}$ max/EDV (see Abstract 164 figure 1A) and co-existent impairment of diastolic function as indicated by medial E: E' values (see Abstract 164 figure $1 \mathrm{~B}$ ), which was associated with an appropriate increase in LA volume (70.3, 82.6 and $72.8 \mathrm{ml}, \mathrm{p}<0.05$ baseline vs $6 \mathrm{~h}$ ). Following this, there was a recovery of both systolic and diastolic indices. In addition, another marker of systolic function, $\mathrm{S}^{\prime}$ increased after $24 \mathrm{~h}(6.4,6.6,8.2 \mathrm{~cm} / \mathrm{s}, \mathrm{p}<0.05$ baseline vs $24 \mathrm{~h}$ and $6 \mathrm{~h}$ vs $24 \mathrm{~h})$. Concurrent with this recovery, we observed a significant decrease in EDV and ESV at $24 \mathrm{~h}$ post-TAVI (EDV: 94.9 to $83.4 \mathrm{ml}$ $(p<0.05)$; ESV 41.9 to $33.5 \mathrm{ml}(p<0.05))$. These changes in haemodynamics were associated with significant increase of troponin I levels at $24 \mathrm{~h}$ and increase in CK-MB at $6 \mathrm{~h}$ after the procedure (troponin: 0.06 vs $1.19 \mu \mathrm{g} / \mathrm{l}, \mathrm{p}<0.05$; CK-MB 1.6 vs $6.6 \mu \mathrm{g} / \mathrm{l}, \mathrm{p}<0.05$ ). Conclusion Successful TF TAVI results in an immediate improvement in cardiac output. However, overlying this, within the first $24 \mathrm{~h}$ both systolic and diastolic dysfunction occurs. The rise in the markers of myocardial injury suggest this may be due to myocardial stunning and/or some periprocedural myocardial damage. Recovery of contractility is observed after 24 hours.

\section{THE OXVALVE STUDY: ECHOCARDIOGRAPHIC SCREENING FOR VALVULAR HEART DISEASE IN THE COMIMUNITY SETTING: METHODOLOGY, FEASIBILITY AND PRELIMINARY RESULTS}

doi:10.1136/heartjnl-2011-300198.165

${ }^{1} \mathrm{~J} \mathrm{~L} \mathrm{~d}$ Arcy, ${ }^{2} \mathrm{D}$ Ebbs, ${ }^{3} \mathrm{P}$ Grimwade, ${ }^{4} \mathrm{~A} \mathrm{~J}$ Farmer, ${ }^{4} \mathrm{D}$ Mant, ${ }^{1} \mathrm{~B}$ D Prendergast. ${ }^{1} \mathrm{~J}$ ohn Radcliffe Hospital, Oxford, UK; ${ }^{2}$ Didcot Health Centre, Oxford, UK; ${ }^{3}$ Bampton Medical Practice, Oxford, UK; ${ }^{4}$ Department of Public Health and Primary Care, University of Oxford, Oxford, UK

Introduction Valvular heart disease (VHD) is poorly researched in comparison with other areas of cardiovascular disease. Principle limitations are the diverse nature of patients with VHD, inability to identify individuals at the earliest stages of disease and lack of an appropriate investigational infrastructure. Studies addressing the contemporary epidemiology and natural history of VHD are scarce but demonstrate an increasing prevalence in the elderly, associated with significant morbidity and mortality. Cohort studies in the USA are ongoing but there are no European or UK studies to date. We have developed a large scale, prospective community echocardiographic screening study within the adult Oxfordshire population, to determine the epidemiological characteristics of VHD in the UK for the first time, to assess the acceptability of echocardiographic screening for VHD, and establish cohorts with well-characterised genetic and echocardiographic phenotypes for future study. Herein, we present preliminary data for the first 1050 patients, with enrolment ongoing. Methods Patients $>65$ years, registered with participating general practices (GP) and with no known VHD, were invited to attend their GP surgery where routine demographic and cardiac data were collected and a focused examination undertaken. Participants underwent a standard transthoracic echocardiogram (TTE) according to
British Society of Echocardiography guidelines. The threshold for inclusion in the screen positive group was deliberately low to capture all manifestations of VHD. Participants were given preliminary results, before completing a shortened Spielberger STAI questionnaire. Results Uptake was 46\% (age range 65-96 years; male to female ratio $1: 1.1)$. VHD was detected in $33 \%$ of participants and prevalence increased with increasing age (see Abstract 165 figure 1). Mitral regurgitation and aortic regurgitation were the most common lesions detected (present in $17 \%$ and $14 \%$ respectively). The majority of VHD was graded as mild (84\%); only $1 \%$ of VHD detected was severe. The majority of participants (99\%) described themselves as calm or relaxed at the time of screening; none expressed significant levels of worry or tension. $98 \%$ would be prepared to undergo repeat echocardiography as screening for VHD.

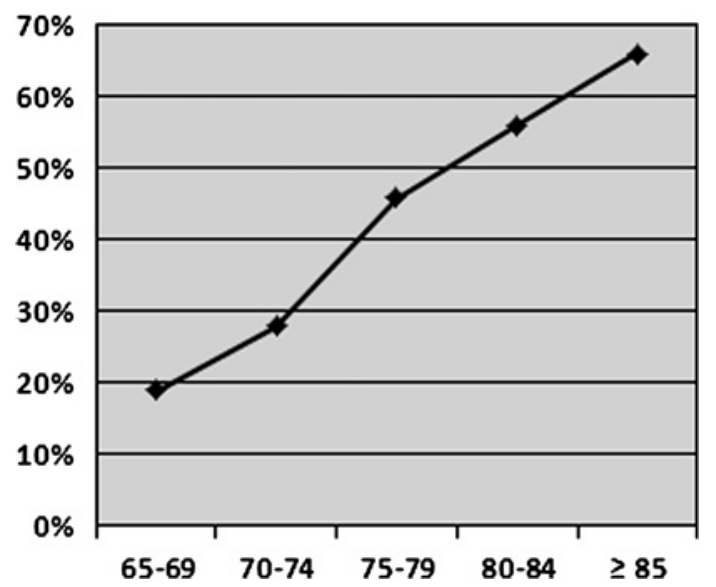

Abstract 165 Figure 1 Prevalence of VHD in $\geq 65$ s by age group.

Conclusions The prevalence of VHD in adults aged over 65 in the Oxfordshire population, using a low threshold for detection, is approximately $33 \%$ and increases with age. Mitral regurgitation is the most common lesion, and the majority of detected VHD is mild. Echocardiographic screening for VHD is feasible in the primary care setting and acceptable in this group of patients.

\section{CARDIOVASCULAR MAGNETIC RESONANCE (CMR) TAGGING IDENTIFIES DIFFERENTIAL VENTRICULAR REMODELLING IN PATIENTS WITH BICUSPID VS TRICUSPID AORTIC VALVE DISEASE}

doi:10.1136/heartjn-2011-300198.166

S Bull, J Suttie, N Blundell, J M Francis, T D Karamitsos, A Pitcher, J D'Arcy, B Prendergast, S Neubauer, S G Myerson. John Radcliffe Hospital, Oxford, UK

Background Bicuspid aortic valves (BAV) are a common inherited abnormality with a very high rate of adverse cardiac events at an earlier age than tricuspid aortic valves (TAV). Risk stratification for moderate to severe aortic stenosis, in both bicuspid and tricuspid disease, remains a significant clinical challenge. It is unknown whether pathological left ventricular (LV) remodelling, a strong predictor of adverse cardiac events, differs between patients with bicuspid and tricuspid valvular disease with comparable transvalvular gradients. Cardiovascular magnetic resonance (CMR) tagging provides detailed characterisation of global and regional contractility, and is a powerful investigative tool in the assessment of myocardial disease. We therefore assessed left ventricular strain (using CMR tagging), valve morphology and LV hypertrophy in patients with bicuspid and tricuspid aortic valve disease matched for transvalvular gradient.

Methods 42 subjects were recruited in total: 24 patients with moderate to severe BAV (age $55 \pm 15 \mathrm{yrs}$, female $21 \%$, peak trans- 
aortic velocity $3.1 \pm 0.6 / \mathrm{ms}$, LV mass $172 \pm 48 \mathrm{~g}$; SBP $127 \pm 14 \mathrm{~mm}$ $\mathrm{Hg}$ DBP $76 \pm 10 \mathrm{~mm} \mathrm{Hg}$ ) and 18 patients with velocity-matched TAV (age $74 \pm 6$ years, female $28 \%$, velocity $3.1 \pm 0.6 / \mathrm{ms}$, LV mass $147 \pm 27 \mathrm{~g}$; SBP $136 \pm 17 \mathrm{~mm} \mathrm{Hg}$ DBP $79 \pm 7 \mathrm{~mm} \mathrm{Hg}$; Abstract 166 table 1). Patients were scanned using a 1.5 T Avanto scanner (Siemens Healthcare, Erlangen, Germany) and basal, mid-ventricular and apical short axis tagging images were acquired. Peak systolic global circumferential strain was calculated at each ventricular level using CimTag2D software v.7 (Auckland MRI Research Group, New Zealand).

Abstract 166 Table 1 Bicuspid vs tricuspid aortic valve disease

\begin{tabular}{lccr}
\hline & $\begin{array}{l}\text { Bicuspid } \\
\text { aortic valve } \\
\text { (BAV) }\end{array}$ & $\begin{array}{l}\text { Tricuspid aortic } \\
\text { valve (TAV) }\end{array}$ & p Value \\
\hline Age (yrs) & $55 \pm 15$ & $74 \pm 6$ & $<0.01$ \\
Female (\%) & 21 & 28 & 0.31 \\
Transvalvular velocity (ms ${ }^{-1}$ ) & $3.1 \pm 0.6$ & $3.1 \pm 0.6$ & 0.50 \\
Left ventricular mass (g) & $172 \pm 48$ & $147 \pm 27$ & 0.04 \\
Systolic blood pressure (SBP) & $127 \pm 14$ & $136 \pm 17$ & 0.04 \\
Diastolic blood pressure (DBP) & $76 \pm 10$ & $79 \pm 7$ & 0.15 \\
Basal circumferential systolic strain (\%) & $20 \pm 3$ & $22 \pm 3$ & 0.04 \\
Mid ventricular circumferential strain (\%) & $19 \pm 2$ & $21 \pm 2$ & 0.07 \\
Apical ventricular circumferential strain (\%) & $17 \pm 4$ & $19 \pm 3$ & 0.04 \\
\hline
\end{tabular}

Results Patients with BAV had significantly greater left ventricular hypertrophy (BAV $172 \pm 48 \mathrm{~g}$ vs TAV $147 \pm 27 \mathrm{~g} ; \mathrm{p}=0.04$ ) despite similar degrees of valve stenosis. Peak systolic circumferential strain was lower (ie, reduced contractility) in patients with BAV than TAV (Basal BAV $20 \pm 3 \%$ vs TAV $22 \pm 3 \% \mathrm{P}=0.04$; Mid BAV $19 \pm 2 \%$ vs TAV $21 \pm 2 \% \mathrm{p}=0.07$; apical BAV $17 \pm 4 \%$ vs TAV $19 \pm 3 \%$; $<<0.04$ ), despite the younger age and lower blood pressure.

Conclusion Ventricular remodelling differs between BAV and TAV patients with equivalent transvalvular gradients. BAV patients, despite being younger and having lower systolic blood pressure, have more severe hypertrophy and lower myocardial contractility. This finding may have implications for monitoring disease progression or more timely medical or surgical intervention in patients with BAV.

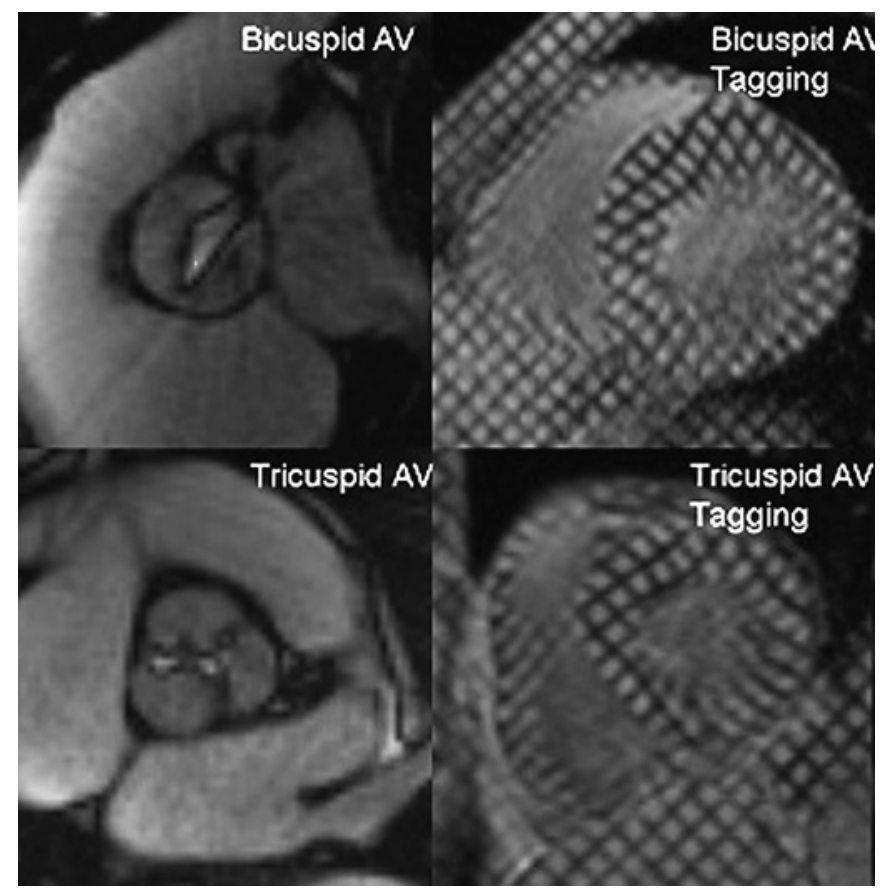

Abstract 166 Figure 1 Velocity matched tricuspid and bicuspid aortic valves showing valve morphology, tagging and cine imaging.

\section{AORTIC REGURGITATION QUANTIFICATION WITH CARDIOVASCULAR MAGNETIC RESONANCE PREDICTS CLINICAL OUTCOME}

doi:10.1136/heartjnl-2011-300198.167

${ }^{1} \mathrm{~S}$ G Myerson, ${ }^{1} \mathrm{~J}$ D'Arcy, ${ }^{2} \mathrm{R}$ Mohiaddin, ${ }^{3} \mathrm{~J} \mathrm{P}$ Greenwood, ${ }^{1} \mathrm{~T}$ D Karamitsos, 1J M Francis, 'A P Banning, ${ }^{4} \mathrm{~J}$ P Christiansen, 'S Neubauer. ${ }^{1} \mathrm{~J}$ ohn Radcliffe Hospital \& University of Oxford, Oxford, UK; ${ }^{2} \mathrm{CMR}$ Unit, Royal Brompton Hospital and the National Heart and Lung Institute, London, UK; ${ }^{3}$ University of Leeds, Leeds, UK; ${ }^{4}$ North Shore Hospital, Auckland, New Zealand

Background The timing of valve surgery in asymptomatic patients with significant aortic regurgitation can be challenging. Current indications focus on symptoms and left ventricular (LV) dilation/ dysfunction, but prognosis is already reduced by this time. Quantification of the regurgitation has not previously been used to guide management, likely due to the difficulty of achieving this with echocardiography. Cardiovascular magnetic resonance (CMR) can accurately quantify aortic regurgitation and LV volumes, and we examined whether either could predict symptom development and the need for aortic valve surgery.

Methods 94 asymptomatic patients with moderate or severe aortic regurgitation on echocardiography were identified from four high volume CMR centres. CMR scans were performed to quantify aortic regurgitation and $\mathrm{LV}$ volume indices, and subsequent clinical followup occurred for up to 7 years (mean $2.6 \pm 2.1$ years). The best predictors of progression to symptoms and other conventional indications for surgery were determined.

Results Aortic regurgitant fraction was the best predictor of clinical outcome; area under the curve (AUC) on receiver operating characteristics analysis $0.93(p<0.0001)$, with a specificity of $93 \%$ and sensitivity of $78 \%$ for predicting the progression to symptoms and surgery. Survival without surgery was $88 \%$ for patients with a regurgitant fraction $<37 \%$, compared to $6 \%$ for those with a regurgitant fraction $\geq 37 \%$ (see Abstract 167 figure 1). Regurgitant volume $>38 \mathrm{mls}$ and regurgitant volume index $>25 \mathrm{ml} / \mathrm{m}^{2}$ were also good predictors (AUC 0.91 and 0.90 respectively), though regurgitant fraction had significantly greater predictive power (OR 1.26 compared to 1.09 for regurgitant volume). LV volumetric indices also predicted outcome, but less strongly than measures of regurgitation: LV end-diastolic volume $>267 \mathrm{mls}$ (AUC 0.85), LV end-systolic volume $>88 \mathrm{mls}$ (AUC 0.78). Regurgitant fraction and volume were the only independent outcome predictors on multiple logistic regression analysis. The predictive ability of CMR applied to patients with both moderate and severe aortic regurgitation on echocardiography. Supporting data also comes from a comparison

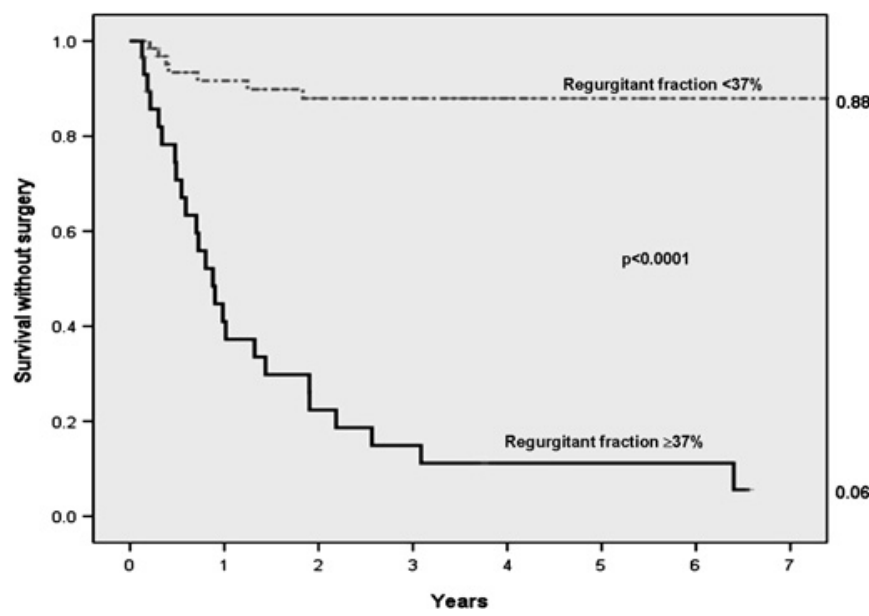

Abstract 167 Figure 1 Kaplan-Meier survival curve showing survival without surgery for conventional indications. 